\title{
Model of colposcopy using polarized light and effective early
}

\author{
Phan Ngoc Khuong Cat, Huynh Quang Linh, \\ Nguyen Ngoc Quynh, Ly Cao Duong.
}

\begin{abstract}
Cervical disease is one of the common diseases, it occurs in women and has a growing tendency. In particular, cervical cancer is one of the most common diseases. The disease can be cured if it is detected early and treated under the guidance of a physician. The usual cervical examination methods are biopsies, and colposcopy. Recently, many studies have applied imaging techniques in the analysis and evaluation of cervical pathology characteristics [1-3]. In this study, we improved the traditional colposcopy with a polarized light source, and captured images with high resolution. Based on the image obtained, we developed image processing algorithms, initially analyzed and evaluated some of the common features of cervical disease
\end{abstract}

Index Terms - colposcopy, polarized

\section{INTRODUCTION}

I some reproductive health studies, the worldwide burden of cervical disease is enormous, with over 500000 cases of cervical cancer diagnosed each year, resulting in 250,000 cases dead. The incidence of cervical disease is highest in developing countries and lowest in Western developed countries, where the screening program has significantly reduced the incidence of the disease [4]. In Vietnam, cervical cancer is the second most common gynecological cancer, after breast cancer. Each year, there are more than 5,000 new cases and more than 2,500 deaths caused by the disease.

Manuscript Received on July $13^{\text {th }}, 2016$. Manuscript Revised December $06^{\text {th }}, 2016$.

This work was supported by National Key Laboratory of Digital Control and System Engineering, and the department of Biomedical Engineering, HCMUT-VNU HCM

Phan Ngoc Khuong Cat, Huynh Quang Linh, Nguyen Ngoc Quynh, Ly Cao Duong are with Department of Applied Physics, Faculty of Applied Science, Ho Chi Minh City University of Technology - VNU-HCM.

Email: pnkhuongcat@hcmut.edu.vn.
A statistic released in 2016 in Vietnam shows that about 14 people are diagnosed with cervical cancer every day, including 7 women dying of the disease. Therefore, the timely detection and treatment of cervical diseases as well as the precancerous urgent [2-3]. symptoms of cervical cancer become extremely In clinical terms, methods to diagnose uterine pathology can be divided into two main directions such as cytology and histopathology. Histology is a technique that uses tissue test results such as Pap smear, ThinPrep, HPV-DNA, and follows the criteria for pathology. Whereas the approach from the cytological level uses results from cervical surface observations by methods such as cervicography, colposcopy, VIA, to evaluate pathological conditions [5-6]. Each method has its own advantages and disadvantages, depending on the conditions of the facilities, the level of disease, the patient's financial ability to choose a suitable method. Among the methods mentioned above, colposcopy is commonly used because it is easy to perform and has many advantages. On the other hand, in developing countries like Vietnam, setting up a colposcopy is possible

Recognize that colposcopy is essential to help doctors diagnose diseases more quickly and effectively. In this study, we developed a model of colposcopy with a polarized light source and using CCD auto focus camera. At the same time, we also built our own management software. It is responsible for controlling the camera, recording and processing the captured image. Thereby it assists the doctor in observing, diagnosing and treating the patient. The initial results were highresolution image quality, feature-specific capabilities, as well as many additional features such as anti-glare on the surface and the observation of blood vessels.

\section{METHODS}

In this study, we developed the optical system by adding a polarized light source using two white and green LEDs. White light observes the cervical image in normal mode, green light is strongly 
absorbed by hemoglobin $(\mathrm{Hb})$, which is an important component in the blood [7]. It helps us to easily detect areas of high blood concentration on the surface of the cervix. Because of the light scattering properties of biological tissues, the polarization angle is altered in the deeper layers of the cervical surface. On the other hand, the cervical surface is well reflective, so the photos are often dazzling and difficult for the doctor to observe and analyze the images. There are some algorithms to handle this problem, but the results are different from the original image [8-9]. Therefore, we will introduce an improved method that uses an optics system consisting of two cross polarized glasses. A polarizer is placed in front of the LEDs, which produces polarized light in a specified direction. The remaining polarizer is placed behind the magnification system. This special technical solution is based on cross-polarized light to enhance image resolution in diagnostic support. The first is the ability to remove glare from the surface of the lesion and the shadow from the field of vision. Secondly, image of polarized light is used to describe the cells and tissues just below the surface of the lesion [9-10].

From the above suggestions, we will simulate the illumination of the light source as shown in Figure 1.

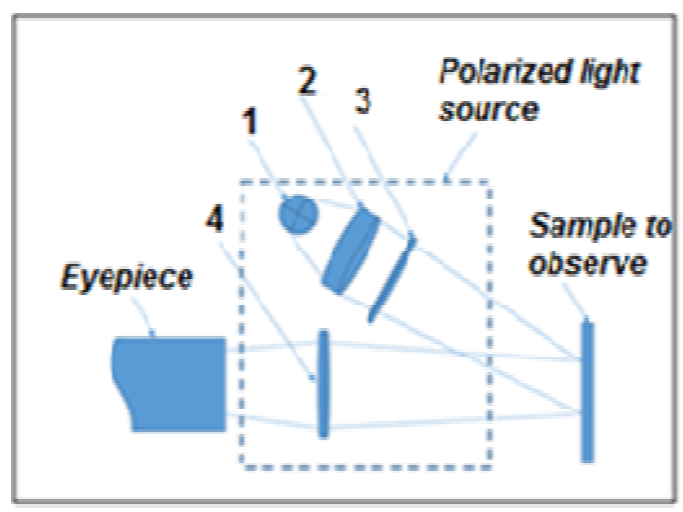

Figure 1. Light source diagram. (1) LEDs; (2) Lens; (3),(4) Polarized glasses

Light with different wavelengths from the LEDs (Figure 1.1) passes through the convergent lens (Figure 1.2) and the first polarizer (Figure 1.3) to the cervical surface. Light reflected or scattered from the surface of the cervix will return through the second polarizer (Figure 1.4) and into the eyepiece of the microscope. The control of the different color modes of the LEDs is done by the control box.
For the control system, we built the model controller with three main components including a System Manager (SM), a Processing Module (PM) and a Colposcope Camera (CC) as shown in Figure 2 .

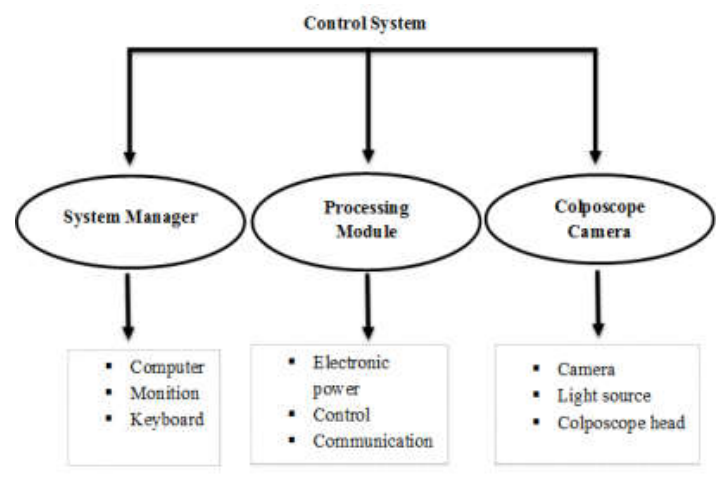

Figure 2. Control system of colposcopy

Firstly, the SM is the computer and computerrelated accessories use to operate the system. It includes the following components: computer, flat monitor, USB keyboard and optical USB mouse, USB wifi. SM controls capture and storage procedures, manages and upload images to Drive. Secondly, the PM consists of three main components: Electronic Power, Control and Communication. Electronic Power is used to distribute the DC voltages needed to operate the system and accepts DC input voltage as +12 VDC. Control uses microcontroller to controls the operation of Colposcope Camera, changes Led color and captures images. It only accepts input voltages as +5 VDC and output as 6 Pin I/O, 2 Pins UART. Communication means that it communicates with SM by Bluetooth, using Universal Asynchronous Receiver/Transmitter (UART) with Baurate 9600 bit/s controlled through $315 \mathrm{Mhz}$ RF remote. Finally, the CC also includes three basic parts: Camera, Light Source and Colposcope Head. For the camera, we use the Full HD digital autofocus camera which uses a CMOS sensor with resolution: 1920x1080 60fps, Output interface: HDMI, Power requirements: $+5 \mathrm{~V}$ max (a) 1A. For light sources, we use Six Leds with two colors: 3 White and 3 Green, controlled by PM. Power requirements:+3V@ 0.5A. It works at a distance of $30 \mathrm{~cm}$ and 12000 Lux Led lighting. For Colposcope Head, it has a polarizer filter and an illumination optics, fastened to the Camera and Light Source.

\section{RESULT}

Based on the theory and goal set, we have developed a model of colposcopy using polarized 
light consisting of six major components as shown in Figure 3. Each component is selected and designed with specialized functionality based on the requirements of the scanning method. The first part is the optical microscope (Fig 3.1), which takes over the image magnification function. Microscope magnification system is a combination of objective and eyepiece. Object lens is the input port, the eyepiece is not only the output port but also where the eye to observe. During colposcopy and manipulation of the doctor, the cervix must be continuously illuminated. Because the cervix is deep inside the body, it is often lack of light The illuminating part of the scanning process is the light source (Fig 3.2). It is composed of many parts and they are joined together, then it is enclosed by a cylindrical aluminum shell, on the hinged cover to be attached to the objective of the microscope and fixed to the hexagonal screw. In particular, the light source uses polarizing plates, which help the images get high resolution and no blurring due to the presence of water bubbles on the surface of the cervix. With the requirement of designing a colposcopy that can capture images and display them on the screen or store image data. Therefore, at the camera's microscope connection port, we installed a digital camera for being used (Fig 3.3) to obtain a cervical image. Figure 3.4 is a control box, which is installed on the body of the bracket (Fig 3.5), which provides power and adjusts the light source. Not only do manual controls use switch and push buttons, but also camera control program and image processing software are included with the colposcopy.

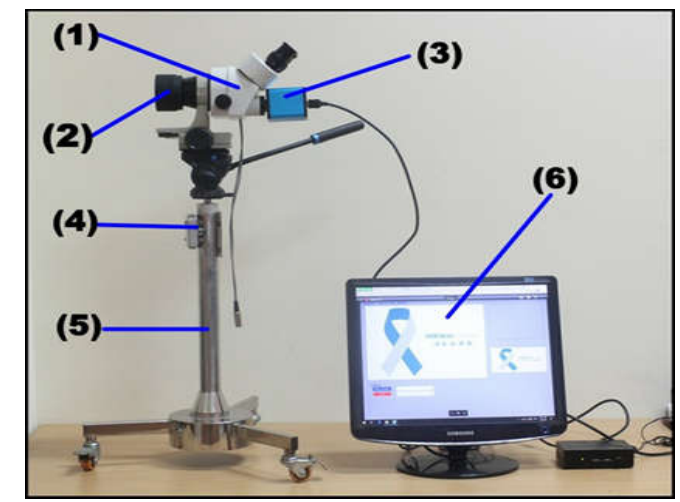

Figure 3. The colposcopy model uses a polarized light source:

(1) Microscope; (2) Light source; (3) Capture camera; (4) Control box; (5) Bracket; (6) Computers.

The interface of the program is simply designed with picture frame and function buttons. The attached program is written in the $\mathrm{C \#}$ programming language, which is responsible for controlling and processing images. The main function of the program is connection the camera to the computer (Fig 3.6), manipulate the camera, store and manage the data. Interface of the program is shown in Figure 4.

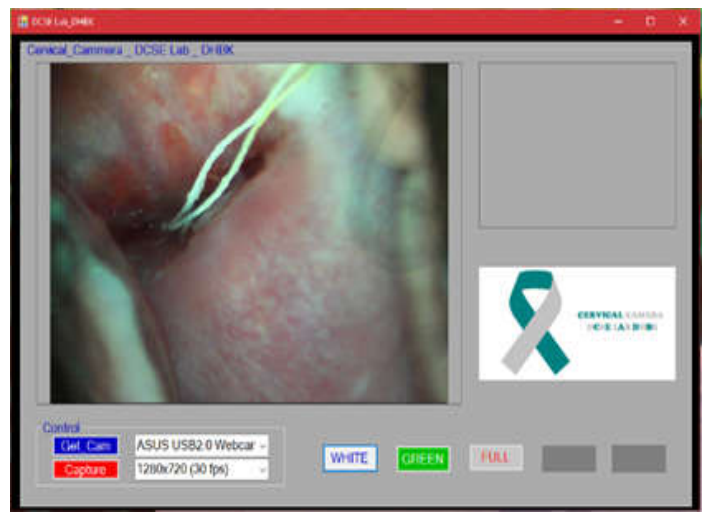

Figure 4. Cervical imaging software interface

The interface of the program is simply designed with an image display panel and function buttons. When you take a picture, the doctor just clicks the capture button. White, green, and full-frame images are captured automatically and continuously and stored in a folder that records the shooting time. The photos will be uploaded to the drive and managed according to the patient's security account without fear of system damage.

With the model of colposcopy using the polarized light source we presented above, we proceed to obtain cervical images with the help of the obstetrician at the clinic. The results are shown in Figure 5.

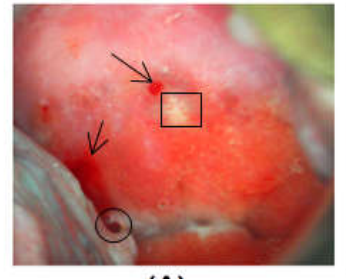

(A)

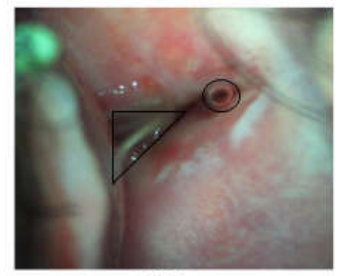

(C)

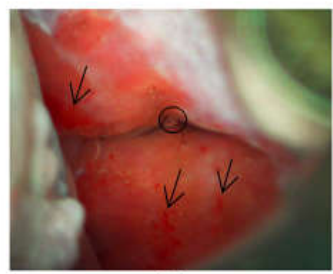

(B)
Figure 5. Cervical polarized image. (A) Nabothian Cyst; (B) Trichomonas; (C) Cervical disease is being treated

Figure 5.A is a cervical image containing Nabothian Cysts recorded by a model colposcopy using a polarized light source. Looking at Figure 5.A, we can see some more clearly the features of the Nabothian Cysts, such as: the cysts are ivory 
white (marked with a square), around the cysts are more redder (marked with an arrow) than the normal area. Similarly, Figure 5.B is a cervical image that is diagnosed as inflamed by Trichomoniasis and is at an early stage. Looking at the picture can be observed in the early stages, the clinical manifestations are not serious, red marks (marked with an arrow) are scattered on the surface of the cervix. Finally, Figure 5.C is a cervical image being treated at last stage. We can clearly see that there is a drug tube (marked with a triangle) in the cervix, the cervical surface almost no appearance of red mark. Moreover, all three images have effectively eliminated the glare and visible water bubbles (marked with a circle) on the surface of the cervix. Therefore, high quality of image recognition has assisted the physician in diagnosing cervical disease faster and more effectively.

\section{CONCLUSIONS}

In this study, based on the theory and the necessity of improving colposcopy equipment, we have successfully built a model colposcopy using a polarized light source and set up a software to manage the data separately. Recorded images have important properties such as anti-glare and visible blood vessels. The results obtained can be seen as a new and objective approach to the development of colposcopy.

\section{REFERENCES}

[1] M.J. Lusk and P. Konecny, "Cervicitis: a review", Current opinion in infectious diseases, vol. 21 , no. 1, p. 49-55, 2008.

[2] Compendium of Research on Reproductive Health in Viet Nam for the Period 2006-2010, Hanoi: UNFPA, 2012.

[3] L. Bruni et al., "Human Papillomavirus and Related Diseases in Viet Nam", Barcelona: ICO Information Centre on HPV and Cancer, Summary Report, 2017.

[4] J. R. Carter, Z. Ding and B. R. Rose, "HPV infection and cervical disease: A review", Australian and New Zealand Journal of Obstetrics and Gynaecology, vol. 51, p. 103$108,2011$.

[5] R. A. Kerkar et al, "Screening for cervical cancer: an overview". The Journal of Obstetrics and Gynecology of India, vol. 56, no. 2, p. 115-122, 2006.

[6] Y. Jusman, "Review Article Intelligent Screening Systems for Cervical Cancer", The Scientific World Journal, 2014.

[7] S. K. Chang et al, "Model-based analysis of clinical fluorescence spectroscopy for in vivo detection of cervical intraepithelial dysplasia", Journal of biomedical optics, vol. 11, no. 2, 2006.

[8] A. Pierangelo et al., "Polarimetric imaging of uterine cervix: a case study", Optics express, vol. 21, no. 12, p. 14120-14130, 2013

[9] D. G. Ferris et al., "Enhancing colposcopy with polarized light", Journal of lower genital tract disease, vol. 14, no. 3, p. 149-154, 2010.
[10] Jim O'Doherty et al, "Sub-epidermal imaging using polarized light spectroscopy for assessment of skin microcirculation", Skin research and technology, vol. 13, no. 4 , p. $472-484,2007$

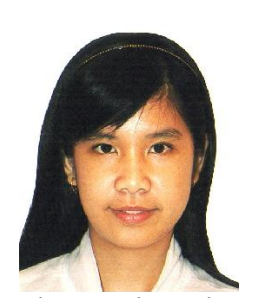

Phan Ngoc Khuong Cat received the B.S. and M.S. Degrees in Photonics and applycations from the Voronezh state university, Russia, in 2009. She is now with the Department of Applied Sciences, Hochiminh City University of Technology - 268 Ly Thuong Kiet Street, District 10, Ho Chi Minh City, Viet Nam. Her research interest includes the optics and photonics, image processing in biomedical and fabrication of medical equipment. (Email: pnkhuongcat@hcmut.edu.vn)

Assoc. Prof. PhD. Huynh Quang Linh is now Dean of the Faculty of Applied Sciences, Hochiminh City University of Technology - 268 Ly Thuong Kiet Street, District 10, Ho Chi Minh City, Viet Nam. His research interest includes the basic research: Modeling and simulation of photon and ionizing radiation penetration through matter, biomedical cybernetics, optical polarization etc and application research: Biosignal processing (ECG, EEG), biomedical image processing, bioinstrumentation etc. (Email: huynhqlinh@hcmut.edu.vn)

Nguyen Ngoc Quynh is the final- year student in Biomedical Engineering, engineering physics, at Hochiminh City University of Technology - 268 Ly Thuong Kiet Street, District 10, Ho Chi Minh City, Viet Nam. (Email: nguyenngocquynh95@gmail.com)

Ly Cao Duong is the final- year student in Biomedical Engineering, engineering physics, at Hochiminh City University of Technology - 268 Ly Thuong Kiet Street, District 10, Ho Chi Minh City, Viet Nam. (Email: lycaoduong@gmail.com) 


\title{
Mô hình thiết bị soi cổ tử cung đa bước sóng và hiệu quả ban đâu
}

\author{
Phan Ngọc Khương Cát, Huỳnh Quang Linh, \\ Nguyễn Ngọc Quỳnh, Lý Cao Dương
}

Tóm tắt - Bệnh lý cổ tử cung (CTC) là một trong những bệnh phổ biến ở phụ nữ, có xu hướng ngày càng gia tăng,trong đó ung thư CTC là một trong những bệnh thường gặp. Bệnh có thể chữa khỏi nếu phát hiện ở giai đoạn sớm và được điều trị theo sự hướng dẫn của bác sĩ. Các thủ thuật thăm khám CTC thông thường là sinh thiết, và soi CTC. Gần đây có nhiều nghiên cứu ứng dụng kỹ thuật xử lý ảnh trong phân tích, đánh giá các đặc tính bệnh lý CTC [13]. Trong nghiên cứu này, chúng tôi cải tiến thiết bị soi CTC truyền thống với nguồn sáng LED phân cực đa bước sóng, đồng thời thu ảnh với độ phân giải cao. Trên cơ sở hình ảnh thu được, nhóm phát triển các thuật toán xử lý ảnh, bước đầu phân tích, đánh giá một số đặc tính thường gặp trong bệnh lý CTC.

Tù khóa - soi cổ tử cung, phân cực. 